\title{
An Embodied Artistic Inquiry into Attachment-Oriented Therapeutic Relationships
}

\author{
Emma K. Mamis ${ }^{1}$ (D)
}

Accepted: 24 October 2020 / Published online: 30 November 2020

(C) The Author(s) 2020

\begin{abstract}
In this study, I utilized an embodied artistic inquiry self-study to explore my experience of attachment in the therapeutic movement relationships (TMR) created as a dance/movement therapy intern at a psychiatric residential treatment center for children. The research was guided by three questions: How do I experience the TMR with children in a psychiatric residential treatment setting using attachment theory? How is my personal attachment style influencing and guiding the therapeutic relationship? How does my identification of salient moments relate to my own attachment style and aesthetic preference? Data were collected using journal entries that reflected on the researcher's experience of attachment, saliency, and Tortora's D.A.N.C.E. qualities of attachment (Clin Soc Work J 38(1):37-50, https://doi. org/10.1007/s10615-009-0254-9, 2010). I analyzed the data using discussion and Authentic Movement with a research consultant in order to synthesize and describe the experience of each salient moment. Repeated movements included grounded and unstable walking, changing of levels, core-distal movements, circling and carving arms, and recuperation. The themes that resulted from repeated movements and discussion with the research consultant include foundational movements, holding discomfort, connection to a specific client, and playfulness. These results reinforced the importance of stability and self-awareness for a therapist especially in relationship to how their movement and nonverbal preferences may have been learned from attachment relationships. Furthermore, results show the impact of saliency and the clinician's aesthetic preference. In addition, the results reflected the strong relationship among nonverbal qualities of attachment and the TMR. These results suggested that qualities of attachment underlie the effectiveness of the TMR. Although limitations of the study prevented me from drawing correlative conclusions, the therapist may be able to strengthen the therapeutic relationship by targeting primary attachment models, and suggestions for further research are included.
\end{abstract}

Keywords Attachment - Therapeutic movement relationship · Therapeutic relationship $\cdot$ Self-study $\cdot$ Saliency $\cdot$ Nonverbal

Extended author information available on the last page of the article 


\section{Introduction}

I stood in the room with ten children ranging in age from 8 to 13 . It sounded like chaos as they each watched and took turns trying to make one client laugh. I turned my head to see one client standing a few yards away from me begin to yell. She appeared upset and told me that I ignored her on purpose, and I would not give her a turn. As I stood there and listened to take in her words, I found myself responding in a way that was uncomfortable and unnatural to my body. I raised my voice and matched her tone as I stood equally tough and sturdy to explain my process of selecting clients. As I projected my voice towards her, she stopped. She walked towards me, lowered her voice, and engaged in a conversation about her feelings and actions. Then she relaxed and joyfully took her turn. This client had never stood so close to me and always communicated discomfort towards standing in closeness with others. Yet in this interaction, she experienced something that allowed her to reduce our physical distance and engage in a relationship that regulated her emotions.

While working with foster children in residential treatment, I sensed the effectiveness of utilizing attachment theory as a model for treatment and engaging my clients who have complex trauma and disrupted familial relationships. As a site that utilizes relational and attachment theories to inform their work, I observed the effectiveness of other clinicians at my site utilizing attachment theory to enter the relationship. Clinicians primarily utilized a relational framework and attachment theory to guide their understanding of the clients' actions and responses to relationship. In their interactions with clients, clinicians worked to demonstrate healthy interpersonal interactions and support clients in developing secure attachment in order to support their wellbeing later in life.

In my work as a counselor and dance/movement therapy intern, I also had a preference for developing my clinical work through a relational and strengthbased framework. This means emphasizing the relationship between the therapist and client (as well as the client and others in their life) as the basis of my therapeutic work. In addition, I recognized and worked from the strengths that a client presents and understand their behaviors as useful and positive for them in some way. The relational therapy model values empathy and aims to facilitate a transition from disconnection towards connection (Banks, 2006). The trauma that many of my clients experienced often took place in their earliest (attachment) relationships. Because these clients have experienced very few, if any, relationships with healthy connection, the importance of utilizing a relational framework in order to demonstrate secure and healthy relationships is further reinforced.

I worked with clients as a dance/movement therapy intern. I led group and individual sessions, in addition to strengthening my relationships by spending time on the milieu. The American Dance Therapy Association defines dance/ movement therapy as the "psychotherapeutic use of movement to promote emotional, social, cognitive, and physical integration of the individual, for the purpose of improving health and well-being" (American Dance Therapy Association, 2014). I think of dance/movement therapy as the use of the body, movement, and 
creativity to express, cope, understand, and work towards larger biopsychosocial goals. Dance/movement therapy uses action and movement in the treatment process. It also allows the clinician to understand, connect, and relate to their clients on a somatic level. I understand somatic not only as relating to the body, but as an inclusive term relating to body, mind, and spiritual self, including thoughts, sensations, feelings, emotions, images, and movements (Imus, 2018; Siegel \& Bryson, 2011).

As a dance/movement therapist, my understanding of attachment reached beyond the cognitive experience and framework. However, I did not have another dance/ movement therapist at this site with whom to explore this understanding. When I dove into the literature, I was faced with an equal level of mystery and convoluted responses to my desire to understand and pinpoint what experiences I should be looking for in my relationships. I found myself reading about infant regulatory disorders, attachment assessments, and attaching to milieu staff (Barton \& Robins, 2000; Moses, 2000; Page, Heller, \& Boris, 2008). However, this did not fulfill the knowledge I was seeking. I wanted to deepen my understanding of the implicit aspects of attachment relationships by using my own body and relationships to learn about this topic.

The purpose of this study was to bridge a gap in the literature on somatic experiences of attachment within the therapeutic relationship. I approached this goal by utilizing my own experiences and deepening my understanding of myself in the therapeutic relationship. Without a dance/movement therapist at my site, this study allowed me to delve deep into the fundamental use of my body in relationships and understand where, how, and with what parts of my body I was engaged in my clinical work. This reinforced the uniqueness and my own experience of dance/movement therapy beyond interventions that explicitly used dance and movement metaphor. I rarely used movement as a metaphor for my clients because it was hard for them to understand. However, I sensed that I connected with clients nonverbally by utilizing my body as a therapeutic tool. I developed my research as a way to better understand this.

As I developed my research methods and understood my methodology, I understood meaning through salient experiences. I explored this by reflecting and embodying a response to salient moments in my relationships with clients. I will define and discuss this further in the next section. Saliency and my aesthetic preferences became a core part of this work as an embodied artistic inquiry and my work begged the final question of, how does my identification of salient moments relate to my own attachment style and aesthetic preference?

\section{Salient}

For the purpose of this study, salient and saliency were understood as something (a moment, thought, or impression) that felt important in response to my research question. This experience of importance stems from tacit knowledge which acknowledges the significance of the researcher's intuition (Moustakas, 1990). The reasoning for this may be unknown, but saliency arose through my aesthetic preference and 
felt (through movements, feelings, sensations, thoughts, or images) necessary to further engage (Imus, 2018; Siegel \& Bryson, 2011). Salient moments may have been interactions that continued to sit with me throughout the day or a particularly intense or odd moment. Each of these moments involved a specific interaction with a single client, rather than an interaction with a whole group. Saliency also arose through the movement analysis, which may have included repeated movements or qualities or portions of movement that stood out to the mover or witness. These movements or qualities may have stood out because of aesthetic preference or their uniqueness compared to other movements.

This study included an exploration of saliency and my attachment experience as a clinician. The next chapter explores the current literature of attachment and the therapeutic relationship. I also explored the current literature on childhood trauma and residential treatment as it related to my experience and the experiences of my clients. The later chapters detail the study, outcomes, results, and further suggestions for research.

\section{Literature Review}

In this study, I explored the concepts of attachment and the therapeutic relationship at a somatic and nonverbal level when working with foster children in psychiatric residential treatment. These children have all experienced trauma and neglect, which has impacted their development. There is extensive research on the impact of trauma and the effectiveness of residential treatment. In addition, there is literature on the usefulness of attachment theory and the therapeutic relationship as effective aspects of treatment. These topics are broad and well researched. However, this literature is vast and would be impossible to fully describe in this literature review. A brief description of each is included, but the focus is primarily on the nonverbal experience and therapeutic effectiveness of attachment and the therapeutic relationship.

\section{Foster Children}

In the United States, many children enter the foster care system because abuse and/ or neglect that occurred in the home (Child and Family Services Review, 2017). This means that the children have witnessed violence in the home or have been in abusive situations, often resulting in trauma. This trauma has a significant and often lasting effect on them throughout their life (Child and Family Services Review, 2017; Cicchetti \& Toth, 1995; Felitti et al., 1998). Because of these experiences, children are likely to develop insecure attachments with unavailable or unsafe caregivers. They have developed altered working models for being in the world in order to survive (Bowlby, 1969; van der Kolk, Roth, Pelcovitz, Mandel \& Spinazzola, 2005). The emotional response to these events (trauma) can look many different ways, especially in children (American Psychological Association, 2015). These responses to trauma can become ineffective ways of coping when they are no longer in an unsafe environment. These experiences can lead to psychiatric hospitalization, 
the need for intensive and specialized support, or residential treatment in order to develop effective ways of managing emotions, caring for oneself, and building healthy relationships.

\section{Foster Children in Residential Treatment}

Children and adolescents within the foster care system who require immediate psychiatric care may be placed in a psychiatric hospital. Psychiatric hospitals can provide for intense psychiatric needs such as suicidal intent and psychotic episodes (Tuma, 1989). When a short hospital stay is not sufficient for managing the needs of the child, the child may be placed in residential treatment. Here, the child typically lives in a dormitory style building that has a highly structured program and intense mental health support; however, these facilities are less restrictive than psychiatric hospitals (Bates, English, \& Kouidou-Giles, 1997; Curtis, Alexander, \& Lunghofer, 2001). In 2017, an estimated $7 \%$ of children in the foster care system were placed in residential treatment, and most children who enter residential care have experienced chronic violence and/or trauma (Children's Bureau, 2018; Knoverek, Briggs, Underwood, \& Hartman, 2013). Residential treatment is ideally the last resort when the community cannot support the child safely in any other way; however, the actual criteria, structure, and execution of determining placement varies greatly (Bates et al., 1997; Curtis, et al., 2001; Zegers, Schuengel, Van IJzendoorn, \& Janssens, 2008). When placement is determined, the transition to a residential setting can be distressing and disruptive as it often detaches a child from any successful supports prior to placement. However, it appears that this distress fades with effective treatment (Little, Kohm, \& Thompson, 2005; Zegers et al., 2008).

\section{Attachment}

Attachment (Bowlby, 1969) is one of the earliest ways we, as human beings, learn to survive and connect with our caregiver(s). The brain develops connections and patterns through observing and being in relationship with others, which may be more or less effective depending on the nature of the relationship (Siegel, 2015). We learn to connect and understand the world through this lens that is modeled after our relationships with our caregiver(s) (Bretherton, 1995; Goldberg, 1995). Attachment theory was initially developed by John Bowlby and Mary Ainsworth to describe the basis of the infant relationship with a caregiver as a schema for interacting with the world (Bretherton, 1995; Goldberg, 1995, p. 1). Attachment patterns have been studied over many years and are divided into four major patterns by Ainsworth: secure, avoidant, ambivalent or resistant, and disorganized/disoriented (Ainsworth, Blehar, Waters, \& Wall, 1978). Attachment patterns are primarily categorized by the infant's response to separation and reunion with their caregiver (Ainsworth et al., 1978). An infant with secure attachment may experience some distress during separation but is easily comforted by the return of the caregiver. In addition, these infants are able to explore the world around them with the proximity of their caregiver (Ainsworth, 1985). They are confident in the availability of their caregiver who is sensitive and 
responsive to providing for the infant in a time of need. Secure attachment is developed through a series of interactions that include frequent and extended physical contact with the caregiver in infancy, soothing responses to distress, and a regulated environment that allows the infant to develop awareness of consequences (Ainsworth \& Wittig, 1969). Secure attachment relationships may also provide a holding environment (Winnicott, 1960) and containment (Bion, 1962). When the relationship is holding and containing it provides for the physical and emotional needs of the child (Winnicott, 1960). This includes managing and supporting the infant in understanding difficult emotions such as fear and pain (Bion, 1962).

Insecure attachment patterns (avoidant, ambivalent, and disorganized) have varied responses to separation with their caregiver and often have not provided a response to the infants physical and emotional needs (Ainsworth, Blehar, Waters, \& Wall, 1978). Insecure responses to separation are developed through either uncertainty in the caregiver response (avoidant) or an expectation that there will be no response form the caregiver (ambivalent) in the time of the infants need (Ainsworth et al., 1978). The final insecure attachment pattern, disorganized, is a less predictable response that appears to be disorganized version of one of the other three patterns (Ainsworth et al., 1978). The impact of these attachment patterns impacts the development of the individual. Individuals with secure attachment build positive views of the self and others. When the attachment is insecure the child begins to view the world as a reflection of this relationship including negative models of their self and poor adjustment (Bowlby, 1969; Knoverek et al., 2013; Mikulincer \& Shaver 2012). This includes children who are abused or neglected of which over $80 \%$ develop insecure attachment patterns (Cook, Blaustein, \& Spinazzola, 2003). However, through stable relationships, therapeutic intervention, and support, individuals can restructure their neural patterns and shift their internal models to develop a new framework for relationship (Belsky, 2002; Siegel, 2015).

At its earliest moments, attachment is experienced through the infant's body. The infant connects and explores the world through touch, sensation, and somatic experience while caregivers engage through touch, mirroring, and modeling relationship, emotions, regulation, and boundaries (Beebe, Lachmann, \& Jaffe, 1997). Tortora $(2006,2010)$ further describes the nonverbal and bodily attachment experience between an infant or young child and a caregiver through her Ways of Seeing approach. This focuses on the qualities of movement in children to assess and intervene through nonverbal means (Tortora, 2006, 2010). These qualities are rooted in the multi-sensory experience of the attachment relationship, which has a regulatory nature for the developing infant (Greenspan, 1992; Greenspan \& Wieder, 1993; Hofer, 1995, 2003). These qualities are summarized with the acronym D.A.N.C.E. (dyadic, attachment-based, nonverbal, communicative, and expressions) (Tortora, 2010). The categories are quality of eye gaze, facial expressivity, use of space, quality and frequency of touch and/or physical contact, body shapes, tempo of nonverbal movement style, vocal patterns, and nonverbal behavior and regulation (Tortora, 2010). Tortora (2010) states that the information gained from these categories reflects the attunement during spontaneous interactions. Tortora provides definitions and details regarding each of these categories in her Ways of Seeing (2010) article. Research on the nonverbal experience of attachment focuses on the experience of 
the infant or young child and the outcomes of these relationships for the infant or young child. There is very little stated about the experience of caregiver (parent) in relationship with the infant or child and what the caregiver may experience when providing this relationship.

The impacts of attachment experience continue throughout the lifetime and continue to impact interactions, experiences, and internal working models for relationships (Bowlby, 1979; Pietromonaco \& Barrett, 2000). Individuals form these internal working models as memory structures. Internal working models lead to expectations of other people in relationships based on previous relationships (Mark Sossin, 1999). When attachment is not developed securely, internal working models include negative self-models and poor emotion regulation (Bowlby, 1969; Knoverek et al., 2013; Mikulincer \& Shaver, 2012; Siegel, 2015). When these are modeled after unpredictable relationships the infant may experience uncertainty, fear, and distance from others (Siegel, 2015).

In adulthood, there appears to be a continued impact of insecure attachment. For example, attachment security was associated with the personality trait of conscientiousness in adulthood as seen through a studying the relationship between Adult Attachment Interview security and a personality trait questionnaire of undergraduate students (Roisman et al., 2007). In another study, the relationship between attachment and actions was assessed in a relational mirroring game. This game involved adult participants producing mirroring motions with or without a designated leader. The outcome showed that adults with insecure attachment were more rigid and less exploratory in relationships (Feniger-Schaal et al., 2016). Correlations to conscientiousness from Roisman et al. (2007) and the mirror game from Feniger-Schaal et al. (2016) are two studies among many that explore the impact of attachment across the lifespan.

\section{Attachment as a Treatment Model}

The attachment model allows therapists to understand how clients relate to others and to help clients develop new models for engagement in the social world (Blakely \& Dziadosz, 2015; Sonkin, 2005). When clinicians can provide a secure attachment, clients have demonstrated significant improvements in behavior and management of distress compared to those who did not provide a secure attachment (Wolfe \& Wittenborn, 2012). Therapists should provide an environment that reflects holding and containing qualities (Winnicott, 1965; Bion, 1962). Through this treatment model, clients can adjust their internal working models (Belsky, 2002) with a sense of safety and empowerment while building secure and collaborative relationships with adults (Moses, 2000; Substance Abuse and Mental Health Services Administration [SAMHSA], 2018). When clients are able to learn from the therapeutic relationship and shift their internal working models, they are also more likely to seek support from others in their life to manage difficult experiences (Wolfe \& Wittenborn, 2012).

In order to serve as an attachment figure for clients, therapists need to understand their own experience of attachment and what it is like to engage as an attachment figure. One systematic way to do this is through the Adult Attachment Interview (AAI) (Main \& Goldwin, 1998). This allows adults to identify and develop 
coherence regarding their attachment experience and understand the way it impacts their lives today (Roisman et al., 2007). This interview focuses on current relationships and memories of childhood in order to classify the adult's attachment pattern (Main \& Goldwin, 1998; Roisman et al., 2007). The AAI focuses on classifying this relational pattern, but it does not describe the cognitive or body-felt experience of engaging as an attachment figure. This experience includes feelings, emotions, sensations, images, and thoughts regarding the connection with another individual (Siegel \& Bryson, 2011). Because this is lacking in the literature, it is unclear what a therapist may experience on a somatic level when they serve as an attachment figure or use an attachment model with clients.

\section{Therapeutic Relationship}

The therapeutic relationship is a central part of the therapy process. This relationship represents the connection and bond between the client and the therapist which includes feelings, attitudes, and their modes of expression. These experiences can be expressed subtly and verbally (Gelso \& Carter, 1985). This relationship can function as a part of the healing itself. The therapeutic relationship has a large amount of qualitative overlap with the attachment relationship such as positive feelings upon reunions, specific ties to the individual, a safe haven for distress, and emotional availability that allows exploration (Obegi, 2008). Because many of these factors are the core of both attachment and therapeutic relationships, it can be difficult to discern which relational process or parts of each process are active in the ultimate outcome (Obegi, 2008).

\section{Therapeutic Movement Relationship}

The therapeutic movement relationship (TMR) is a physical and movement experience of the therapeutic relationship for a dance/movement therapist (Young, 2017). This physical experience includes kinesthetic attunement, embodied self-awareness, sensory experience, and movement to create change (Fogel, 2009; Tortora, 2010; Vermes, 2011). Young's phenomenological study concluded on the definition of the TMR:

The TMR is a shared presence of the body, mind, and spirit between the dance/movement therapist and client where healing occurs within the safe containment of a creative collaboration, and results in a resonance. Rooted in the tents of humanism, it is born out of one's ability to kinesthetically attune and respond to the implicit and explicit movements of another informed by knowledge of one's own body sensations and movements as well as continual observation and assessment of the client's movement. (Young, 2017)

Just as the therapeutic relationship serves as a major component of change, TMR represents this experience for a dance/movement therapist. This includes the use of empathy that is experienced on an embodied level, kinesthetic attunement, shared 
presence and movement connection, contained creative collaboration, and human connection (Young, 2017).

\section{Experience of the Therapist}

Numerous studies have examined the impact of therapist's attachment styles on the therapeutic relationship and therapeutic outcomes (Black, Hardy, Turpin, \& Parry, 2005; Cologon, Schweitzer, King, \& Nolte, 2017). These studies suggest that the security of the therapist's attachment in their own lives, including the therapist's reflective functioning, correlate to stronger therapeutic relationships, increased openness to exploration by clients, and more positive outcomes after therapy (Cologon et al., 2017). While each of these areas continues to be studied and refined, I was unable to find any studies that describe the experience of a therapist serving as a secure attachment figure for clients.

In particular, studies have examined and classified attachment by utilizing the Adult Attachment Interview (Main \& Goldwin, 1998). In this interview, therapists are able to gauge and elicit "thoughts, feelings, and memories regarding early attachment experiences" (Petrowski, Pokorny, Nowacki, \& Buchheim, 2013). This interview also assesses the individual's mindset towards attachment (Petrowski et al., 2013). The AAI is used to classify the security of an adult's attachment (Main \& Goldwin, 1998). It does not fully describe the experience of attachment within the therapist, including what it is like to serve as an attachment figure. Instead, it utilizes some narrative and memory to understand the therapist's attachment style.

In order to better understand the therapist's experience of the relationship, the themes identified in Young's article may provide greater information here (2017). Young described the TMR as an implicit experience of listening and moving with the client and a fundamental and integral piece of the therapeutic work (Young, 2017). She included presence, relationship with one's own body, intuition, and relationship to space and time (Young, 2017). This information described the TMR as having a very similar relationship to therapy as attachment has to relationships and healthy development. The details of this study may be useful for discerning what experiences are rooted in attachment and which are the therapeutic relationship. These experiences may also overlap.

\section{Conclusion}

The purpose of this study was to explore and expand the literature that describes the therapeutic movement relationship through the lens of attachment theory. There is significant research on attachment theory and the therapeutic relationship. The current body of knowledge does not clearly articulate the practical experience of the therapist at any level of the somatic experience (cognitive, sensory, nonverbal, etc.). This study began to bridge this gap and utilized an artistic inquiry to describe my experience of using attachment theory to guide the TMR. This description 
highlights my individual experience with the therapeutic movement relationship and its integration with my experience of attachment and salience in clinical work.

My study was guided by the question, How do I experience the TMR with children in a residential treatment setting using attachment theory? In the work guided by this question, I simply wanted to be able to better understand and articulate my experience of attachment in the TMR. As a dance/movement therapist, mover, and artist I have always had the opportunity to express myself without words and allow that to be satisfying. However, as I move forward in my journey as a clinician, I have found that it is not enough to simply believe and understand what I am doing at a nonverbal level within myself. It is equally important to be able to articulate and share this experience with clients, clinicians, and others that I meet. In order to do this, I need to understand my experience cognitively and consciously so that I can express it verbally.

Underlying this larger goal, I felt the need to understand an additional part of myself: my own attachment style. In order to understand my use of attachment, I also need to understand what I am bringing to the relationship. What is mine? What is the client's? What is something else? These are common questions within the therapeutic relationship, and I also applied this to my work with attachment theory. I asked the question, How is my personal attachment style influencing and guiding the therapeutic relationship? In the next sections, I describe my methods and procedure for answering these research questions in order to begin to bridge the gap in the literature. I describe the methodologies and validation strategies to support my research.

\section{Methods}

\section{Methodology}

In order to retrieve this detailed and highly subjective information on somatic experience and attachment, I utilized an embodied artistic inquiry self-study. An embodied artistic inquiry is a research method which involves using artistic methods for gathering, analyzing, and/or presenting data. It acknowledges the creative process and is integrated with the aesthetic values of the researcher (Hervey, 2000). This research methodology allowed me to take advantage of aesthetic preferences and creative ways of processing through movement-which may have been developed through the attachment process. This methodology aligned well with my personal paradigm of constructivism, which acknowledges that truth and meaning are created from the individual's experience and interpretation (Von Glasersfeld, 2005). With my goal to explore my experience as an individual, embodied artistic inquiry was a well-suited methodology. In addition, this methodology allowed me to recognize and utilize the experience of saliency as a way of knowing (Hervey, 2000). This experience of saliency relates directly to my aesthetic preferences. Experiences of saliency are often displeasing and outside my aesthetic preference. Finally, through embodied exploration-including movement improvisation-my creative process came forward as a guide to describing, understanding, and synthesizing the information from my body. 


\section{Participant \& Setting}

I was the researcher and participant in this study. At the time of this study, I was 23 years old and reaching the final few months of my dance/movement therapy and counseling internship at a children's psychiatric residential facility. I was a full-time student and am a middle-class woman of mixed-race (British and Malaysian), and supported by my family. This support includes financial assistance, support towards my emotional needs, career, and hobby choices. I was raised in a home with my biological parents and siblings. I also had a strong relationship with my biological grandparents. My parents and grandparents have never been divorced. I have experienced secure attachment and strong familial relationships that influenced my actions as a clinician. I conducted my research by reflecting on experiences and interactions with clients at the psychiatric residential facility where I was a dance/movement therapy intern. I provided both individual and group therapy sessions. The clients with whom I interacted ranged from ages 8 to 13 and were primarily Black/AfricanAmerican or White. The clients were all placed in this facility by the Department of Child and Family Services, have disrupted family relationships, show symptoms of Posttraumatic Stress Disorder, and exhibit difficulty building healthy relationships. I collected data at the facility in an office space where I was alone after working with clients in therapy sessions. I analyzed the data in the private office of my research consultant, which included an open space for movement.

\section{Procedure}

\section{Data Collection}

I collected data through guided journal entries (see "Appendix 1"). I identified a brief interaction that felt salient at the end of each day I interned at a residential psychiatric treatment center for children. I identified at least one salient interaction per week with a maximum of three per week. The interactions described in each journal entry were individual interactions between a single client and me. These interactions occurred in different settings including individual sessions, on the milieu, passing in the hallway, and before, during, and after groups. All of the interactions were with clients I had built a relationship with in group therapy and on the milieu over a 6-month period. I also met with a number of the clients for individual therapy. In order to honor the authenticity of the experience and allow myself time to focus on each journal entry, I did not identify more than one interaction per day. With the identified interaction, I completed the journal entry by recording and reflecting my perceptions and experiences of the interaction. If there was no salient interaction, I allowed myself to write a journal entry describing the experience of not having a salient moment. I described sensations, movements, images, feelings, and thoughts related to the experience of not being draw to a specific interaction or moment in my day (Imus, 2018; Siegel \& Bryson, 2011). These journal entries from days that did not seem to have salient moments were of similar length and responded to each 
category just as entries about salient moments did, but the interaction identified was less specific than when saliency arose. I completed the journal the same day as the interaction before leaving the site. I completed eight journal entries over 7 weeks.

I began each journal entry by describing the interaction briefly, exploring why an interaction was salient and what that experience was, and exploring how an interaction related to my attachment experience and the greater concept of attachment. Next, I utilized Tortora's (2010) Ways of Seeing nonverbal categories of attachment to explore the somatic experience in order to extract information about the nonverbal experience of attachment. These categories are quality of eye gaze, facial expressivity, use of space, quality and frequency of touch and/or physical contact, body shapes, the tempo of nonverbal movement style, vocal patterns, and nonverbal behavior and regulation. Finally, I concluded each journal entry with space for additional notes, which I only occasionally utilized. I spent $30 \mathrm{~min}$ to an hour writing each journal entry.

\section{Data Analysis}

I analyzed the data using self-directed improvisational movement and verbal discussion with a research consultant. Each journal entry was analyzed 1 to 2 weeks after it was written. Analysis occurred four times as a singular hour for one piece of data and two times for two hours for two pieces of data. No more than two pieces of data were analyzed at a single meeting. The data (journal entries) were taken to my research consultant who discussed my journals with me and served as a witness towards movement response. We began by reviewing and discussing the different parts of each journal entry. The conversation was fluid as we discussed different connections between the parts, connections to the client's relational history, connections to my own attachment experiences, and similarities from previous pieces of data. My research consultant encouraged me to clarify anything that was confusing and deepen my reflections on the experience as we discussed.

After we discussed the journal entry, we moved into the next step of the analysis. This portion of the analysis was an artistic exploration through self-directed improvisational movement. The consultant supported the creation of a safe environment for exploration. In each session, I moved my response to the journal entry for 15 min. During this movement session, I moved freely and allowed my body to initiate and guide my responses to the journals. My research consultant witnessed my movement. In addition, she kept track of the time and used a singing bowl and soft voice to indicate when the $15 \mathrm{~min}$ were complete. In our use of improvisational movement, my research consultant created a space that unintentionally replicated many aspects of the holding environment (Winnicott, 1965).

After moving, I took my time to reenter the physical space and prepare to recount my experience verbally. I spoke about my movements by describing different movements that I recalled enacting. My research consultant then responded with her own experience of witnessing me, including her feelings and the movements she saw. After we each shared, we continued to engage in a verbal discussion in order to synthesize the journal entry. This discussion involved furthering my understanding of the meaning and experience of different movements, as well as drawing connections 
to previous journal entries, movements, and themes. After the end of most sessions, I identified a movement — often because it was salient, unique, or repeated — to film as a record and summary of the analysis. In addition, I recorded any notes and highlights from these sessions in order to document my conclusions and experiences. All documentation occurred within 24 hours of the analysis session.

\section{Validation Strategies}

In a qualitative study and artistic inquiry, data validation can be difficult. I have ensured reasonable validity of my data by using a research consultant, rich description, and clarifying the bias of the researcher (Creswell \& Miller, 2000). The use of a research consultant throughout the data analysis process served to provide awareness to my biases and assumptions. The research consultant was an individual with whom I had no relationship prior to the research process. The research consultant has extensive experience in the field working across the lifespan as a clinical counselor, dance/movement therapist, and Authentic Movement practitioner. With these experiences, the research consultant was able to provide validation and external checking to the researcher. The research consultant provided awareness and engaged in a discussion regarding my worldview and experiences to ensure an honest and truthful process. The research consultant also served as an expert witness to the movement analysis process.

I utilized rich descriptions in the reporting of the data collected, including references and descriptions of journal entries and movement. I intentionally included extensive descriptions of the movements and long quotes from my journals. These rich descriptions of the experiences were intended to allow the readers to understand how I came to my conclusions and to allow space for the reader to develop their own conclusions about the information and experience (Creswell \& Miller, 2000). Additionally, these passages allowed the reader to develop an in-depth description and understanding of my experience in order to answer my primary research question regarding the experience of the therapist.

Finally, bias is an integral and inherent part of the research and is influential and important to the conclusions that are reached (Creswell \& Miller, 2000). The research methods and questions rely on the individual and biased experience of the researcher for answers. In order to understand an individual's attachment experience and experience of saliency, bias is required. For this study, the aesthetic preference for certain qualities of movement and preference for particular feelings in relationship related directly to the data I collected. In addition, the preference towards certain movements, styles of movement, and grounding exercises are specific to me and not intended to be directly replicated by another clinician. Rather, another clinician could follow the general themes to develop their own movements and conclusions. In this study, I had a bias for certain qualities within saliency. I was often drawn towards moments of anger because anger is more uncomfortable to me and uncommon in many of my relationships. In addition, my style of movement and ways of engaging with clients were often rooted in my personal preferences. I often initiated a softening of my posture, an enclosing torso, mild eye contact, or a hand on 
the shoulder of a client. These were my personal preferences for engaging that I learned from my own early relationships. They were common in my family. While this bias was always present, I also learned to recognize when it was not useful in my clinical relationships. In the following sections, I have described and highlighted my bias throughout the results and discussed the impact that these biases had on the outcomes.

\section{Results}

In this study, I sought to describe and understand the therapeutic movement relationship through the lens of attachment theory. Through the research process, I uncovered a relationship between my attachment style, saliency, and aesthetic preferences that suggests these may be intertwined. In my results, I described movements that repeated throughout my analysis and the themes that arose as a result. Together these themes and movements demonstrate how my attachment style influences my therapeutic relationships and aesthetic preferences. The descriptions and themes provided in this section reference my individual experience as a developing clinician and intern. My experience and understanding of attachment in the therapeutic relationship will continue to develop alongside my professional and personal development both explicitly and implicitly. Upon concluding my analysis, I have acknowledged that, in order for me to fully understand the relationship between my attachment style and my therapeutic relationships, I would need to conduct much more extensive research.

As I completed my eight journal entries, I began to recognize themes and commonalities across the collection of journal entries from writing and initial discussion. Among the eight journal entries, each journal entry involved a shift in my experience of connection to the client. While some journal entries described experiences where my actions resulted in an experience of stronger connection with the clients, other entries describing increased relational distance between the client and me. In these experiences, I was often surprised by the unusual amount of disconnection that resulted. In two entries, I described an almost identical action that resulted in opposing outcomes from the client in the journal entry. I also wrote a collection of entries about a single client with whom I experienced attachment qualities very strongly. Journal entries and interactions involved a variety of emotions including anger, near-dissociation, joy and laughter, calmness, and neutrality.

Throughout the research process, I also developed awareness of my personal attachment style. This was an increased understanding about how I build relationships and how I prefer to connect and engage. These actions and styles are preferences that are necessary to acknowledge. Without acknowledging these preferences, I may be missing opportunities to connect with clients and pressing my own relational preferences onto clients. My personal secure attachment style developed from my relationships in my infancy and childhood. In these relationships, I was attuned to and my caregivers were responsive to my needs by providing comfort and security in times of distress (Bowlby, 1988). In these secure relationships, I witnessed and engaged with particular nonverbal responses. It was from these responses that I built 
a movement profile that involved softening of the body including eye contact, facial expression, and torso. This also included slowing down and allowing for myself and the client to take our time. I wrote about my own memories of experiencing a touch on the shoulder from my parents in journal entry 2 :

I can recall many moments in which those who I attached with entered in through a soft touch of the shoulder. This placement feels comforting but not invasive. The additional qualities of slowing time but directness allows for comfort and clarity without disregarding emotion.

In addition, I utilized soft tone, playfulness, and reinforced healthy boundaries. I described my feelings towards different vocal tones in journal entry 3. "I noticed my own discomfort with the use of tone, likely because this was not a way of relating that I experienced in my own attachment relationships". In journal entry 6, I described memories of playfulness and learning to set boundaries I experienced in my own childhood:

It reminds me of times of laughter and pushing the limits of comfort. I think about laughing so hard that it became uncomfortable, but comfortably being able to say stop and having my parent respond. A tickle represents a form of healthy touch and it exudes joy when the contact is initiated in the right moment.

My statements in this journal refer to my own memory of the use of tickling to engage in healthy touch and playfulness in my own family. These memories include information regarding the quality and safety that I experienced in physical contact with my caregivers. The safety (including boundaries) and playfulness included here aligns with the D.A.N.C.E category (Tortora, 2010). In addition, I was able to utilize the tickle with clients who had I had a strong relationship with and ensured that it was safe for them as a way to engage in playful and healthy touch with clients. While tickling is not always an appropriate way for a clinician to engage with clients, I found that developing safe and playful relationships seemed to reflect attachment on a qualitative level. This was one quality of my own attachment that developed in my explicit awareness during the journaling process. In addition to playfulness, I became aware of my preference for softening my vocal tone and body. My understanding of these qualities and the impact they had on my therapeutic relationships was deepened through the movement process and developed into themes of this research through discussion with my research consultant. I discovered their effectiveness when developing relationships. In the next section, I will detail my self-directed improvisational movement experience that allowed me to better understand my nonverbal experience in the therapeutic relationship and how it connects to attachment, including developing secure relationships.

\section{Repeated Movements}

After completing my journals, I brought them to my research consultant. We discussed the journals then engaged in an improvisational movement practice. The 
movements were a response to these journal entries. The movement experience was central to my results and conclusions. During these movement sessions, I began to repeat movements from previous session. Through deepening my understanding of these movements, I was able to develop themes and conclusions of this study. The movements that repeated themselves during improvisational sessions are grounded walking, unstable walking, changing levels, core-distal movements, circling of the arm, carving arms through space, and recuperative movements (e.g., child's pose). These movements were video recorded at the conclusion of the movement session. I also discussed them verbally with my research consultant during the reflective discussion of each session. The following is a description of the repeated movements that reflects the videos and improvisational movement experience. Each repeated movement is described here in the present tense in order to create a more embodied experience for the reader and to align with my movement practices.

\section{Grounded Walking}

I pull my feet in towards my torso to stand. My feet root into the floor with weight pressing deeply into the ground. My head is held tall and my hands rest at my sides. My torso and core expand and contract as I sense my breath flow through my body. I am present. I slowly begin to lift my foot from the floor and move it slightly forward. I place my foot with intention as I feel the sole of my foot plant and reconnect to the floor. This repeats with each step moving slowly and intentionally. The steps in this walking create a circle around the edge of the room.

\section{Unstable Walking}

I am standing. I feel my breath flow through my nose into the depth of my belly. I feel my weight pressing through my feet, but I am having trouble sinking it into the depths of the floor. My feet feel shaky and I feel my arches move back and forth. This shakiness reverberates through my body and my breath becomes harder to regulate. As I lift my foot to move forward, I feel my standing leg attempting to root down, but it is not possible. As I place my foot, I feel off balance-as if I could fall at any moment. My body feels insecure and unstable with the simplest movement: walking on flat ground.

\section{Changing Levels}

I always begin moving by laying on my back and return to this position or seated on my knees throughout movement sessions. I move from this prone position and roll onto my side pulling my knees in. I place the balls of my feet in the floor like a squat. I place my hands on the floor with my fingers spread wide and deepen my weight into my hands and shoulders. My weight is balanced between my upper and lower halves. Then, with a smoothness, I move all my weight into my feet and bring myself into standing as I roll through my vertebrae. I am standing tall, feet into the floor and head held tall. Throughout my movement sessions, I move in this way from laying to standing. At times, I repeat movements while seated on my knees. 
My movement exploration exists in a constant flow between laying, seated on my knees, and standing. It is a cyclical progression of these levels, rarely moving or exploring space and levels in other ways.

\section{Core-Distal}

Core-distal movements are movements that organize the body by first connecting to the individual's core and allowing the core to radiate out and begin connection with others (Hackney, 1998). The experience of reaching from my center outward occurs frequently throughout my embodiment and exploration of my journal entries. In this experience, there is no singular movement that occurs, but rather a consistency in the type of movement. For example, I am seated on my knees and crawling my fingers back and forth along the floor. Each movement comes from my core as my arms stretch and crawl along the floor. The circling arm (described below) also represents this experience. In another example, my arms move softly stretching directly in front of me. My fingers curl slightly then guide my arm back to my chest. Each arm follows the next in a circular movement that brings connection to and from my core.

\section{Circling Arm}

I am standing. My feet are rooted deep into the floor. My arms float up to shoulder height and create a t-shape. I leave my left arm floating at shoulder level. My right hand guides my arm forward and outstretched away from my body. My fingertips guide my arm to enclose. My right hand grazes my left hand then my left arm, and my hand continues to move across my chest. I return to the $\mathrm{t}$-shape and repeat this motion. I am drawing a circle with my fingertips while maintaining light and soft qualities throughout my body. As it repeats, my torso joins in. I begin reaching farther and circling with my upper body as it follows my arm and hand. Occasionally, this movement repeats as I sit up tall on my knees with my shins on the ground.

\section{Carving Arms}

I am standing. My feet are rooted deep into the floor. This movement is no longer a clear circle. My arms move with a rounded quality as they carve and snake through my forward space. They begin to carve and explore around my head and to either side of my body. They move and engage my torso and back. My arms also explore the space behind me while my feet remain planted and my torso engages a slight twisting.

\section{Recuperative Movements}

After exploring movements while standing and seated, I find moments to relax and recuperate. Most often, I sit on my knees with my shins on the floor. My head and torso curl over into a child's pose. My forehead is in contact with the floor allowing my weight to sink and yield deeply. I lay my arms bent alongside my head and torso with my fingers and forearms sinking into the floor. Occasionally, I roll over 
onto my back. I am lying flat and yielding into the floor. One arm comes over my forehead and eyes, allowing the weight of my hand and arm to provide weight and relaxation to my eyes and forehead.

\section{Themes}

Through the process of discussion with my research consultant and the recurrent experiencing of these movements, I discovered a set of themes. These themes arose through the experience of repetition and saliency from movement and journal entries. These themes are (1) foundational movements prior to enacting connection, (2) the experience of being a container, (3) a necessity to hold my own discomfort, (4) pacing, (5) repeated client, and (6) playfulness and improvisation.

\section{Foundational Movements}

Through the processes of writing journal entries, discussion, and embodiment, I uncovered a series of factors that highlighted my experience providing attachmentoriented relationships with my clients. The first and most repeated piece was my experience of groundedness as a precursor to my response and interactions with clients. This groundedness showed up in my grounded walking throughout my movement responses. Grounded walking held my regulated state and stability. It was the ideal place of being in myself in order to connect and explore the relationship with my clients. During my interactions with clients, I wrote about how I was able to maintain groundedness and presence. I described feelings of "increased calmness and regulation...I had [a] deepened connection to my internal experience" (Journal Entry 8). In journal entry 3, I experienced increased emotional arousal and "I increased ground[ing] and remained where I was".

This movement repeated itself almost identically throughout my analysis. This movement symbolized where I needed to be in relationship with myself in order to explore with and respond to clients. When this walk became unstable, I struggled to connect with clients in a successful relational way. I experienced much more disconnection and emotional discomfort when I could not find this grounded place physically. My own state of regulation is a key factor in my ability to serve as an attachment figure and relational guidepost for clients. The development and result of this theme aligns with the category of nonverbal behavior and regulation from Tortora (2010). Here she writes about the importance of observing how "nonverbal behaviors support self-regulation" (Tortora, 2010, p. 42). In my experience, I utilized foundational movements to ensure that I remained regulated in relationship with my client, by doing so I was able to support further coregulatory actions and stronger interventions for my clients.

\section{Container}

The therapist as a container or a boundary was a metaphor that occurred throughout my training and is reflected as an aspect of secure relationships in the literature 
(Bion, 1962). This metaphor found its way into many of my movement responses. As I found myself standing and entering into my grounded walk, my steps created a circular border around the edge of the room that served as a container. I also created the container through my circling arm movement. This container-and my own ability to contain and hold the clients' emotions-was foundational to the therapeutic relationship.

When my steps became unstable, I had trouble connecting with the client and understanding what actions I should take in the moment. In these moments, I sensed that I was struggling to contain or hold the space to support the client. Journal entries 4 and 5 both included metaphors of barriers between the client and me. I described a feeling of being "shut out from his playing and unable to find a way of entering in with him. I simply observed on the outside" (Journal Entry 4). When I felt restricted and struggled with my ability to connect, my experience as a container shifted and became unstable. In this unstable container, clients were less open and held stronger boundaries. At times, these boundaries felt uncomfortable to me, but served as a learning experience and contributed to the conclusions.

\section{Holding Discomfort}

In the unstable or shaky container, I experienced discomfort within myself. However, I held each moment of discomfort inside me in order to better serve connection with the client. I did my best not to show this discomfort to my clients, instead I showed responses that aligned with their verbal requests, maintained safety, and/or mirrored their interactions. In many of my journal entries, I commented on the ways in which I built a relationship and strengthened my connection with clients. I discussed how each of these ways of connecting was familiar or unfamiliar. I explored the experience of unfamiliarity and its relationship to discomfort. In the narrative that opened this piece, I discussed the experience of raising my voice to match the level and tone of a client. This narrative was drawn from journal entry 3 where I described the areas that I felt uncomfortable:

I noticed that I was matching the client's tone very clearly. This is not a way I generally approach or interact with clients which is why it felt so strong for me. However, I also noticed that the interaction was effective, and the client was able to reduce her distance to me...I noticed my own discomfort with the use of tone, likely because this was not a way of relating that I experienced in my own attachment relationships...I prefer close space and softening in my interactions, so this felt unusual for me.

This experience felt extremely uncomfortable in the deep pit of my stomach. With the existing power dynamics between clients and therapists, there was nothing I had more distaste for than the experience of raising my voice in response to a client. However, as a dance/movement therapist, I have learned to attune to clients on various levels. In this moment, I attuned to the client's vocal tone as a way of connecting. This served my relationship with the client more than any previous action I had engaged in with her. In this moment, I had to hold my own preferences for connecting and my own expectations about what healthy, acceptable, and appropriate 
relationships should look like. Instead, I attuned to the needs of the client and utilized a combination of vocal patterns and posture to strengthen my connection with the client. By doing this, I was able to mirror a quality of the client's actions which ultimately resonated most with her. Although I was holding discomfort, I was also taking advantage of the D.A.N.C.E. category of vocal patterns to support connection (Tortora, 2010). As with many therapeutic connections, I held discomfort in half of my journal entries. The experience of discomfort was also described as a feeling of being "unable to help" (Journal Entry 2), "detached" (Journal Entry 4), "hard to engage eye contact" (Journal Entry 5), and "blurry" (Journal Entry 5).

Each experience of discomfort was a different sensation in my body, but each one was related to my action or a response to my action. My actions were rooted in the ways I learned to regulate my emotions and understand relationship through my attachment memories. These memories guided the way in which I initiated interactions. I discovered a preference to engage in movements and interactions that were similar to those I experienced in my own attachment experiences, such as consistency, boundaries, safety, and support for emotional regulation. The way that these attachment experiences were enacted with me included a soft voice, a hand on the shoulder, and the offering of space; these were similar to the actions that I used to engage clients. However, when clients responded in unexpected ways or were unresponsive to my preferred ways of engaging, I had to push myself into discomfort in order to support the client. In these moments, I adapted my responses to better respond to the needs of the client and provide security. Through holding discomfort in these different moments, I began to acknowledge the different places where my own ways of connecting, relating, and providing security for clients may not work. I needed to adjust my preferences and my natural flow in order to better meet clients.

\section{Pacing}

In supporting and adapting my ways of connecting with clients, I turned to my internal sense for pace, time, and flow. Timing is often an important part of therapeutic work. In my journal entries and movement explorations, I found that my patience and allowance of flow and authenticity were key factors in the positive experiences in the client-therapist relationship. This patience allowed me to attune to the tempo of nonverbal movement, a category from Tortora (2010). I describe this experience in my first journal entry, I wrote: "I was not rushing her into the group room which feels [like] an important part of the interaction related to the positive outcome from the interaction. I met her at a slower pace". I described many of the interactions as aligned and connected to my breathe, while others were "similar to a call and response" (Journal Entry 6). The pacing of journal entry 3 was described as "if we were going back and forth as if passing a ball and taking a step forward each time until we were able to meet in the middle". One of the interactions was described as lacking "rhythm and tempo-less" (Journal Entry 4). I continued to experience this pacing in my self-directed improvisational movement sessions described next.

In my experience of moving, I initiated a gesture with my arms. After this movement was enacted and completed, I changed levels and moved into a moment of recuperation. These recuperative movements were described as recuperative 
movements in repeated movements. I found recuperation through stillness and yielding into the floor. After finding recuperation, I reentered movement with the same gesture. The second time, the gesture would often be similar but also included more of my torso and full body, becoming a fuller movement. I returned to recuperation and repeated this cycle multiple times in a single movement session. Through reflection, I came to understand this movement pattern to be representative of the pacing of the relationship. I found that strengthening bonds took time and could not be done in a singular action but returned to and revisited in order to fully develop. This idea reflects the ideas of attachment theory which suggest that attachment is developed over a series of repeated interactions (Bowlby, 1988).

\section{Repeated Client}

Upon the completion of writing journal entries, I noticed that I had written three of the journals regarding the same client. In the process of discussion, movement, and continued interaction with this client, I understood the saliency of my relationship with this client that resulted in his presence across my journal entries. In my interactions with this client, I allowed him to lead while we engaged in playful exploration of the body. My experience with him was that the relationship allowed him to express his authentic self. I saw him release the anxiety he held when he was with his peers and explore his world through his body and sounds. In this relationship, there were many qualities that reflected attachment relationships that developed. In addition to providing containment, holding, and responsiveness to emotional need, I also provided physical and nonverbal security. This included the mirroring or repetition of vocal noises, weight sharing, bundling in blankets, and freedom to explore bodily impulse and modes of regulation. These aligned with Tortora's categories including an interaction in journal entry 8. In this entry, I described my attachment and saliency experience with this client:

I sensed the feeling and relationship to attachment immediately as this was occurring. I could imagine myself lying alongside a baby and making this type of eye contact as I mirrored the infantile movements. I felt the playful and infantile nature of our connection...I felt a strong connection to the client in this moment. I sensed a feeling of regulated emotions and safety in the client. I felt he had a sense of freedom as he increased his exploration of movement.

The interactions and experiences often felt much like an interaction I might have had with a baby, which is why I believe it was so salient to me. This experience speaks to the nature of my relationship with this client, which was heavily based in developing healthy attachment by responding to the clients need and supporting the client in emotional regulation and self-awareness.

\section{Playfulness and Improvisation}

In this study, the importance of allowing for playfulness and improvisation was reinforced. Initially, I experienced saliency primarily in response to negative emotions such as anger. However, as I explored saliency and my own memories, I came to 
develop awareness of how different the feeling of playfulness and improvised connections felt. These memories did not always sit as strongly with me at the end of each day because they were experienced as natural to my own ways of connecting with other people. I began to recognize the unique and powerful nature of playful interactions as a representation of healthy and safe relationships which may include a secure attachment. I experienced interactions that exuded emotions such as joy and laughter as an example of alternative ways of exploring a relationship. Additionally, I similarly experienced improvised interactions that existed beyond the planned and expected structure; these created examples for ways of being and developing strong positive connections. Improvisation and play are a fundamental mechanism of creative arts therapy according to Imus (2016). The relational experience of these concepts and their connection to attachment may further explain the process of their effectiveness in creative arts therapy, including dance/movement therapy. An example of an improvised and playful interaction was identified in journal entry 6:

I sit in a circle with clients as we all straddle our legs and stretch to one side. I reach past my foot to tickle the foot of the client to each side...This client responded by tickling my foot as I turned away and repeated the interaction of brief laughter and smiles together...The saliency of joy [emerges] as I see flashes of many positive moments with a smile. I see laughter and positivity stream from the faces in my memory. Yet it does not sit as strongly and repeat with the intensity that moments of anger or unpredictable emotions do.

Each of these themes depicted an important aspect of my experience of the therapeutic movement relationship through the lens of attachment theory. In the next section, I will discuss the importance of these themes and describe the benefit of understanding these themes. Finally, I connect my conclusions to their clinical implications and provide recommendations for clinicians to utilize this work. I also provided suggestions for future research.

\section{Discussion}

I began this study with the goal of better understanding my experience of the therapeutic movement relationship through the lens of attachment theory. Through allowing myself to reflect, engage in discussion, and respond through movement, I have developed some clarity. I have identified the importance of developing and acknowledging myself, understanding my own relational preferences, and holding my discomfort. I recognized the impact and experience of playfulness and improvisation in building relationships. I increased awareness regarding the relationship between saliency and types of emotions. It is in these places that I have begun to answer my research questions.

As I increased my awareness and discovered repeated movements, I built more awareness about myself and how my own relational style influences the therapeutic relationship. It was necessary to understand and attend to my own ways of relating in order to see how they were influencing the relationship. I developed an awareness of how my movement and interaction preferences were related to early relationships. 
Actions from my memories and ways that I learned prior to my formal education on therapeutic interventions showed up in the actions I took with clients. My first and most comfortable responses to clients were rooted in ways that I preferred to connect: softening the torso, placing a hand on the shoulder, softer vocal tones, or tickling the foot. These actions reflect the interactions that I had with others in my childhood. They reflect moments that I recall experiencing for myself as well as witnessing between my family members. These preferences came up first and were the easiest response but did not always serve my connection with the client. I cannot know if utilizing a different engagement with the client would have been more effective in this study, but it was important to acknowledge my own reasons and desires for a given action for future reference in my future work with clients.

When I was not connecting in relationship to my own preferences, I was often attuned to what seemed to be the client's ways of connecting in a relationship. This could be very uncomfortable. I felt unstable and responded in ways that were against my own relational patterns. However, it was more effective to connect through the client's patterns before providing the client with additional information (verbal or nonverbal) on alternative ways to connect and relate to others. It was important for me to recognize my own biases and discomfort in order to accurately attend to the client's needs. This was only possible when I acknowledged and understood my movement patterns and relational preferences. By responding, acknowledging, and recognizing my own discomfort, I was more able to engage stabilizing and regulating skills within myself. This allowed me to better attune to the client's nonverbal communications in the relationship and increase connection with the client.

My experience of internal tracking and connecting with clients relationally allowed me to have patience and openness for the relationship to guide therapeutic outcomes. I experienced joy and a desire to continue the connection when relating through an attachment framework. By bringing my fully present and grounded self to clients, I became a connection where clients could begin to explore new relational patterns and difficult emotions. In this building this connection, I utilized curiosity, openness, acceptance, and love or COAL. This is a description of mindful awareness that supports interpersonal attunement and relationships (Siegel, 2007). Utilizing COAL, I have allowed clients to safely explore their internal experiences and external representation of the self. I experienced clients showing the unique aspects of the self and trusting the process of self-exploration. We explored this through playfulness and improvisation as a way to better understand the self through mirrored experiences and find basic human connection. As the facilitator of these incredible moments with clients, I wrote about my experiences of laughter, joy, and connection with clients in my journals. In journal entry 8 , I wrote:

I felt the playful and infantile nature of our connection. I experienced joy and this feeling sat with me and carried forward through our interactions...I felt a strong connection to the client in this moment. I sensed a feeling of regulated emotions and safety in the client. I felt he had a sense of freedom as he increased his exploration of movement...I felt increased calmness and regulation after as I had a deepened connection to my internal experience. 
The experience depicted in the journal was also represented in my repeated movements of core-distal and carving arms. These came to represent connection and exploration, respectively, as I noted in my movement sessions.

In addition to deepening my understanding of my own experience, I have increased my understanding of how I identified salient moments during my data collection process. For me, saliency began as an experience that related to discomfort and dysregulation. As I wrote my journals, I found myself being drawn to these uncomfortable encounters. In general, these were outside of my connection preferences. They required me to engage alternative ways of connecting or recognize the ineffectiveness of my preference in the moment. My aesthetic preference when interactions were salient was to note difference that typically included an angry emotional state of clients and myself. As my research consultant brought this into my awareness, I strived to deepen my understanding of saliency and pushed myself to explore different sensations. I allowed myself the openness to explore other experiences by reflecting more deeply on my day before selecting a salient experience. I began to recognize positive, joyful, sad, and depressive moments as salient despite the different qualities. As I wrote in my journal entries about these moments, I noticed that they represented a different experience of saliency that was often hidden by the strong feelings of discomfort that I felt when anger was present. In journal entry 5 I wrote:

When I reflect on the session, there is not a moment that sticks out. The entire session comes to a blur of evenly valued moments. There was no anger or outwardly strong emotions. This session felt more depressive. I wonder if this depressive feeling is related to the lack of saliency. This may make it hard for the identification of strong or salient emotion when everything felt rather low.

In journal entry 6 , I had a similar experience:

I struggled to pinpoint and experience the saliency in the same way. When the overall day had positive responses and was filled with joy, the saliency does not arise as clearly. It is not a strong memory that I can see in my mind and feel clearly in my body. The saliency of joy as I see flashes of many positive moments with a smile. I see laughter and positivity stream from the faces in my memory. Yet it does not sit as strongly and repeat with the intensity that moments of anger or unpredictable emotions do.

These moments did not initially arise as salient because they did not hold the same anger quality that was initially holding the meaning of salient. Upon further reflection, these interactions felt more normal, comfortable, and well-aligned with my movement and relationship preferences and therefore did not arise as salient. Despite their difference in saliency, there was still importance to therapeutic outcomes and relationship-building in these moments. In my experience, saliency related to my attachment experience and aesthetic preference. Interactions that were the most salient were generally outside of my aesthetics and relational preferences. They were uncomfortable or unexpected and often included anger, which is not a comfortable feeling for me. 
Through the process of understanding my relationship to saliency, I became deeply aware of my own biases towards anger and its place in secure relationships. In my early identification of salient moments, I tended towards moments that involved anger. These stood out most because of my discomfort with anger. Anger was not an emotion that I can recall present in my relationships and the relationships that observed between parents. More specifically, I do not recall witnessing interactions that involved increasing pressure and a loud tone. I do not recall confrontational interactions that included directness, increasing pressure, and loud voices. The result of this experience meant that anger was often the emotion that became salient because it was uncomfortable to me. As I developed this awareness, I also pushed myself to uncover salient moments that were not anger filled. I was able to discover saliency in other places by acknowledging this bias. I found playfulness through this awareness. Finally, because I was able to uncover my own bias towards anger and encounter angry interactions with clients, I am also able to accept and endorse the place where anger can exist within secure relationships. Through anger, I was able to build and strengthen relationships with clients by holding a container and acknowledging that I was able to remain with them in their strongest emotions.

\section{Implications}

As I set out to uncover and deepen my experience understanding how my attachment impacts the therapeutic relationships, I revealed many details of my work as a dance/ movement therapist. I attended to my preferences, sat in discomfort, and explored relationships through movement. Throughout all of this, I was able to increase my knowledge of my skills as a therapist and the ways that I used movement as a part of my work, both broad and minute. Although there is great meaning for me in the simple understanding and knowledge of these aspects, I also have come to larger implications for therapeutic practitioners.

The first is the recognition of the relationship between the TMR and nonverbal qualities of attachment. By referencing and utilizing Tortora's (2010) D.A.N.C.E. categories, I was able to recognize how I was utilizing nonverbal qualities of attachment to build relationships with clients. Through this recognition and description of the actions that I was taking, I found that these actions may have also been categorized as parts of the TMR and general criteria for dance/movement therapy. For example, mirroring body action and attuning to clients kinesthetically are named as structural themes in a study of the phenomenon of the TMR and in the Ways of Seeing approach to attachment (Tortora 2010; Young, 2017). In addition, relationship to space and time is a theme of a TMR (Young, 2017). The descriptions such as "being really present and grounded" and "there with the client in that space of settled place" (Young, 2017, p. 105) align with my experience of foundational movements and pacing. It is likely that the therapeutic process, including the TMR, draw on various aspects of attachment which explains the effectiveness of therapy. Although I cannot definitively conclude if these concepts and experiences are pieces of attachment or the therapeutic movement relationship, this research and past literature suggest that there is a strong relationship between them which makes attachment and the TMR 
nearly inseparable (Obegi, 2008). The qualities of attachment and the TMR are deeply intertwined. It is no surprise that a secure attachment aligns with core qualities of effective therapy and could be used to inform all aspects of therapy regardless of therapeutic framework (Burke, Danquah, \& Berry, 2016).

Based on the themes that developed during this study and their connections to the therapeutic relationship, clinicians in all areas of counseling may consider researching and reflecting on the impact of attachment in their work. While conducting this study, I developed a feeling of how deeply attachment impacts the therapeutic relationship and that this relationship is built upon the clinician and client's various ways of attaching to others. The impact of attachment relationships is ingrained and difficult to ignore when developing therapeutic relationships. With this in mind, I have benefited from the continued development in my understanding of attachment in the verbal and nonverbal relationships with clients. The function of attachment in the therapeutic relationship cannot be ignored but utilized to better understand the connection between the therapist and the client. This includes the different emotions experienced in attachment relationships and how an individual remembers different aspects of sessions based on their comfort with various emotions. By reflecting on the attachment preferences of each individual in the therapeutic relationship, we can begin to understand why and how a relationship is functioning or how a relationship can be best repaired (using verbal and nonverbal attachment strategies). As I continue to develop into a clinician, the constant reflection upon the impact of nonverbal attachment will strengthen my clinical relationships and therapeutic outcomes.

In addition to understanding the attachment of the client, this study reinforced the necessity to develop a recognition of the clinician's individual preferences. This awareness serves as a reminder to me that my preferences may not be the most effective way of connecting with a client. This knowledge was developed by deepening the understanding of saliency and salient qualities in themselves. An individual's aesthetic preferences may lead them to select certain qualities or interactions to focus on while passing over others that feel less important. It is necessary to understand the aesthetics processes that contribute to saliency as this may impact clinical decision-making, note-taking, and the selection of interventions based on what the clinician's preferences indicate. I developed an awareness of my aesthetic process and its connection to discomfort, specifically anger. Without the acknowledgement of my relationship to this emotion, I may be placing too much weight on the emotion as a result of personal feelings. I may also be ignoring this emotion because of my own discomfort. It is in service of the client, that I need to understand my relationship to different emotions. In the process of acknowledging and understanding saliency, we can open their filtering process to noticing interactions that may be outside of their preference but still relevant to the client and their goals.

Finally, as a dance/movement therapist I developed an awareness of our movement preferences through my training. However, I found that I was able to further this by reflecting on my earliest relationships and understanding how my preferences may be rooted in attachment. These minute nonverbal preferences were affecting the therapeutic relationship, and I now have awareness of them. The utilization of reflecting on the nonverbal qualities of attachment may be most useful for clinicians who are not dance/movement therapists as an inroad into understanding and better 
attending to the relational needs of their clients. This process of reflection on nonverbal qualities of attachment and relational preferences should be an ongoing process. The outcomes are not static and should continue to be reflected upon throughout a clinician's career.

\section{Limitations}

Upon completing this study, I found that I learned a great deal about myself as a clinician and my understanding of the therapeutic relationship. The procedure and steps taken in this study are provided and can be utilized as a tool for any clinician interested in developing and deepening their understanding of attachment and the therapeutic relationship. By utilizing a self-reflection process on attachment, I was able to increase my knowledge of myself to better enter relationships with clients. While I elected to utilize a structured journal for this particular study, there are many alternatives and additional steps that are available for developing this knowledge. The structured journal was utilized in order to focus my writing on aspects of the nonverbal experience that may be related to attachment, however, the specific focus of this journal may also be seen as a limitation. An open journaling method may be beneficial as it allows a larger variety of material to develop which may result in different findings. In addition, I relied on my own self-report to determine the security of my attachment and drew on my own experiences in order to support this. By doing this, I was able to focus on my internal experience of secure attachment rather than an imposed decision towards the security of my attachment. This self-report throughout the study poses the limitation of bias which I have attempted to minimize by utilizing validations strategies. It is also important to recall that bias and aesthetic preference are an integral and inherent part of the methodology utilized in this study.

In this study, I did not utilize an Adult Attachment Interview (AAI). It is unknown how this may have impacted the study. It may have reduced the authenticity of my experience of connection with clients and the movement experience by highlighting a certain language or memories that may have been developed in the interview (Main \& Goldwin, 1998). However, the AAI may also have provided additional detail, validity, or different outcomes. This interview could be utilized by clinicians to help frame and develop our self-awareness regarding attachment.

\section{Future Directions}

The work in this study only begins to describe my experience of attachment as a dance/movement therapist in training. This study utilized my self-report of attachment style. Future studies should consider additional ways to understand the therapist's attachment history. Additionally, researchers should consider a larger population pool working in a variety of settings to develop more generalizable data regarding the therapist's experience of attachment in the therapeutic relationship. Finally, it may be necessary to study comparisons between dance/movement 
therapists (who, by definition, use the TMR) and other types of clinicians forming therapeutic relationships. This would provide additional information and clarity regarding the aspects that are specific to the way in which dance/movement therapists form and understand attachment relationships compared to other clinicians.

\section{Conclusion}

In this study, I aimed to describe and deepen my understanding the therapeutic movement relationship through the lens of attachment theory. I asked, How do I experience the TMR with children in a residential treatment setting using attachment theory? I experienced my own somatic self-regulation and grounding as an important factor for the work I embark on. I experienced this relationship as fluctuating between playful and uncomfortable, both of which were necessary in order to build connections and facilitate change. I also asked, How is my personal attachment style influencing and guiding the therapeutic relationship? I found that my attachment style and learned ways of relating are my initial ways of responding to clients in the relationship, but they are not the only way that I can respond. I learned that the effectiveness of this varies and is often unpredictable in the moment. Finally, I explored, How does my identification of salient moments relate to my own attachment style and aesthetic preference? I found that saliency was intertwined with my attachment style and aesthetic preference. My identification of salient moments began with interactions that were outside of my preferences, but I also discovered that I can to dig deeper into my own understanding of saliency. When I did this, I recognized additional important moments with clients that would have otherwise gone unnoticed. Through conducting this study, I have developed an increased awareness around my biases and my preferred techniques as a clinician which will continue to develop and support my work as I improve my clinical and personal work.

Acknowledgements This work was also submitted to the faculty of Columbia College Chicago in partial fulfillment of the requirements for Master of Arts in Dance/Movement Therapy \& Counseling. As such support was received from faculty. In additional, minimal financial support was provided through the Lenore Hervey Research Development Fund.

\section{Compliance with Ethical Standards}

Conflict of interest The author declares that the author has no conflict of interest.

Ethical Approval This research was approved by the academic institution's departmental thesis committee.

Research Involving Human Rights This research was a conducted on the researcher's self and did not include human participants or require informed consents. In order to maintain and protect confidentiality and anonymity, case experiences and journal quotes do not include identifiable details and the facility is not identified. 
Open Access This article is licensed under a Creative Commons Attribution 4.0 International License, which permits use, sharing, adaptation, distribution and reproduction in any medium or format, as long as you give appropriate credit to the original author(s) and the source, provide a link to the Creative Commons licence, and indicate if changes were made. The images or other third party material in this article are included in the article's Creative Commons licence, unless indicated otherwise in a credit line to the material. If material is not included in the article's Creative Commons licence and your intended use is not permitted by statutory regulation or exceeds the permitted use, you will need to obtain permission directly from the copyright holder. To view a copy of this licence, visit http://creativecommons.org/licen ses/by/4.0/.

\section{Appendix 1: Data Collection: Journal Guide}

This appendix provides an outline of questions that were provided to guide each journal. These guides are designed to provide a focus towards the journaling experience in order to highlight the nonverbal and salient experience of each interaction. The body of these questions was modeled from Tortora's (2010) Ways of Seeing approach which provides categories of "nonverbal qualities that make up attachment pattern[s]" (p. 41) called Dyadic, Attachment-based, Nonverbal, Communicative, and Expression (D.A.N.C.E.). A response was provided to each category which may include a description of how the category was used during the interaction by the client and/or therapist. The therapist's experience of sensation, movement, images, feelings, and thoughts (SMIFT) related to each category was also included (Imus, 2018; Siegel \& Bryson, 2011). The SMIFT may be related to the therapist's experience of herself or her experience of the client. If something was not present or was lacking, that experience was also described.

Points to guide journal for initial data collection:

- Briefly describe this interaction

- Reflect on the experience of saliency or lack of saliency related to selecting the interaction

- Reflect on personal attachment style that may have been present in the interaction

- Reflect on D.A.N.C.E. Categories

- Eye Contact

- Facial Expression

- Use of Space (Approach and Spatial Pathways)

- Touch

- Shaping in the Body (Posture or Movements)

- Rhythm and Tempo

- Tone and Vocal Patterns

- Regulation and Arousal 


\section{References}

Ainsworth, M. D. (1985). Patterns of infant-mother attachments: Antecedents and effects on development. Bulletin of the New York Academy of Medicine, 61(9), 771-791.

Ainsworth, M. D. S., Blehar, M. C., Waters, E., \& Wall, S. (1978). Patterns of attachment: A psychological study of the strange situation. Hillsdale, $\mathrm{NJ}$ : Erlbaum.

Ainsworth, M. D., \& Wittig, B. A. (1969). Attachment and exploratory behavior of one-year-olds in a strange situation. In B. M. Foss (Ed.), Determinants of infant behavior (Vol. 4, pp. 113-136). London: Methuen.

American Dance Therapy Association. (2014). What is dance/movement therapy? [Web article]. Retrieved from https://adta.org/2014/11/08/what-is-dancemovement-therapy/

American Psychological Association. (2015). Trauma. Retrieved from https://www.apa.org/topics/traum a/

Banks, A. (2006). Relational therapy for trauma. Journal of Trauma Practice, 5(1), 25-47. https://doi. org/10.1300/J189v05n01_03

Barton, M., \& Robins, D. (2000). Regulatory disorders. In C. H. Zeanah (Ed.), Handbook of infant mental health (pp. 311-325). New York, NY: Guilford Press.

Bates, B. C., English, D. J., \& Kouidou-Giles, S. (1997). Residential treatment and its alternatives: A review of the literature. Child \& Youth Care Forum, 26(1), 7-51. https://doi.org/10.1007/BF025 89364

Beebe, B., Lachmann, F., \& Jaffe, J. (1997). Mother-infant interaction structures and presymbolic selfand object representations. Psychoanalytic Dialogues, 7(2), 133-182.

Belsky, J. (2002). Developmental origins of attachment styles. Attachment \& Human Development, 4(2), 166-170. https://doi.org/10.1080/14616730210157510

Bion, W. (1962). Learning from experience. London: Karnac Books.

Black, S., Hardy, G., Turpin, G., \& Parry, G. (2005). Self-reported attachment styles and therapeutic orientation of therapists and their relationship with reported general alliance quality and problems in therapy. Psychology and Psychotherapy: Theory, Research, and Practice, 78(3), 363-377. https:// doi.org/10.1348/147608305X43784

Blakely, T. J., \& Dziadosz, G. M. (2015). Application of attachment theory in clinical social work. Health \& Social Work, 40(4), 283-289. https://doi.org/10.1093/hsw/hlv059

Bretherton, I. (1995). The origins of attachment theory. In S. Goldberg, R. Muir, \& J. Kerr (Eds.), Attachment theory: Social, developmental, and clinical perspectives (pp. 45-84). Hillsdale, NJ: The Analytic Press.

Bowlby, J. (1969). Attachment and loss: Attachment (Vol. 1). New York, NY: Basic Books.

Bowlby, J. (1979). The making and breaking of affectional bonds. London, England: Tavistock.

Bowlby, J. (1988). A secure base: Parent-child attachment and healthy human development. New York: Basic Books.

Burke, E., Danquah, A., \& Berry, K. (2016). A qualitative exploration of the use of attachment theory in adult psychological therapy. Clinical Psychology \& Psychotherapy, 23(2), 142-154. https://doi. org/10.1002/cpp.1943

Child and Family Services Review. (2017). Section 4: Trauma in the child welfare system. Retrieved December 4, 2018, from https://training.cfsrportal.acf.hhs.gov/section-4

Children's Bureau. (2018). The AFCARS report. (Report No. 25). Retrieved from https://s3.amazonaws. com/ccai-website/afcarsreport25.pdf

Cicchetti, D., \& Toth, S. L. (1995). Child maltreatment and attachment organization: implications for intervention. In S. Goldberg, R. Muir, \& J. Kerr (Eds.), Attachment theory: Social, developmental, and clinical perspectives (pp. 45-84). Hillsdale, NJ: The Analytic Press.

Cologon, J., Schweitzer, R. D., King, R., \& Nolte, T. (2017). Therapist reflective function, therapist attachment style and therapist effectiveness. Administration and Policy in Mental Health and Mental Health Services Research, 44(5), 614-625. https://doi.org/10.1007/s10488-017-0790-5

Cook, A., Blaustein, M., Spinazzola, J., \& Van der Kolk, B. (2003). Complex trauma in children and adolescents: White paper from the national child traumatic stress network complex trauma task force. https://www.NCTSN.org

Creswell, J. W., \& Miller, D. L. (2000). Determining validity in qualitative inquiry. Theory Into Practice, 39(3), 124-130. https://doi.org/10.1207/s15430421tip3903_2 
Curtis, P. A., Alexander, G., \& Lunghofer, L. A. (2001). A literature review comparing the outcomes of residential group care and therapeutic foster care. Child and Adolescent Social Work Journal, 18(5), 377-392. https://doi.org/10.1023/A:1012507407702

Felitti, V. J., Anda, R. F., Nordenberg, D., Williamson, D. F., Spitz, A. M., Edwards, V., et al. (1998). Relationship of childhood abuse and household dysfunction to many of the leading causes of death in adults. American Journal of Preventive Medicine, 14(4), 245-258. https://doi.org/10.1016/S0749 $-3797(98) 00017-8$

Feniger-Schaal, R., Noy, L., Hart, Y., Koren-Karie, N., Mayo, A. E., \& Alon, U. (2016). Would you like to play together? Adults' attachment and the mirror game. Attachment \& Human Development, 18(1), 33-45. https://doi.org/10.1080/14616734.2015.1109677

Fogel, A. (2009). The psychophysiology of self-awareness: Rediscovering the lost art of body sensing. New York, NY: W.W. Norton \& Company.

Gelso, C. J., \& Carter, J. A. (1985). The real relationship in counseling and psychotherapy: Components, consequences, and theoretical antecedents. The Counseling Psychologist, 13, 155-244. https://doi. org/10.1177/0011000085132001

Goldberg, S. (1995). Introduction. In S. Goldberg, R. Muir, \& J. Kerr (Eds.), Attachment theory: Social, developmental, and clinical perspectives (pp. 1-15). Hillsdale, NJ: The Analytic Press.

Greenspan, S. (1992). Infancy and early childhood: The practice of clinical assessment and intervention with emotional and developmental challenges. Madison, CT: International Universities Press Inc.

Greenspan, S., \& Wieder, S. (1993). Regulatory disorders. In C. H. Zeanah (Ed.), Handbook of infant mental health. New York, NY: The Guilford Press.

Hackney, P. (1998). Making connections: Total body integration through Bartenieff Fundamentals. New York, NY: Gordon and Breach.

Hervey, L. W. (2000). Artistic inquiry in dance/movement therapy: Creative alternatives for research. Springfield, IL: Charles C. Thomas.

Hofer, M. A. (1995). Hidden regulators: implications for a new understanding of attachment, separation, and loss. In S. Goldberg, R. Muir, \& J. Kerr (Eds.), Attachment theory: Social, developmental, and clinical perspectives (pp. 203-230). Hillsdale, NJ: The Analytic Press.

Hofer, M. A. (2003). The emerging neurobiology of attachment and separation: how parents shape their infant's brain and behavior. In S. W. Coates, J. L. Rosenthal, \& D. S. Schecter (Eds.), September 11: Trauma and human bonds (pp. 191-209). Hillsdale, NJ: The Analytic Press.

Imus, S. (2016). Home (in) on the range: The practice continuum in the creative arts therapies and allied fields. Keynote address presented at Sharing Space Creatively: Interdisciplinary Collaboration with Creative Arts Therapies, presentation at the 1st Integrated Creative Arts Therapy Conference, Evanston, IL.

Imus, S. D. (2018). A fuller whole: Book review for the whole brain child. American Journal of Dance Therapy, 40(1), 183-185.

Knoverek, A. M., Briggs, E. C., Underwood, L. A., \& Hartman, R. L. (2013). Clinical considerations for the treatment of latency age children in residential care. Journal of Family Violence, 28(7), 653663. https://doi.org/10.1007/s10896-013-9536-7

Little, M., Kohm, A., \& Thompson, R. (2005). The impact of residential placement on child development: Research and policy implications. International Journal of Social Welfare, 14(3), 200-209. https://doi.org/10.1111/j.1468-2397.2005.00360.x

Main, M., \& Goldwin, R. (1998). Adult attachment scoring and classification system. Unpublished manuscript, University of California at Berkeley.

Mark Sossin, K. (1999). The KMP and infant-parent psychotherapy. In J. Kestenberg Amighi, S. Loman, P. Lewis, \& K. Mark Sossin (Eds.), The meaning of movement: Developmental and clinical perspectives on the Kestenberg Movement Profile (pp. 191-209). New York, NY: Routledge.

Mikulincer, M., \& Shaver, P. (2012). An attachment perspective on psychopathology. World Psychiatry, 11, 11-15. https://doi.org/10.1016/j.wpsyc.2012.01.003

Moustakas, C. (1990). Heuristic research: Design, methodology, and applications. Newbury Park, CA: Sage Publications.

Moses, T. (2000). Attachment theory and residential treatment: A study of staff-client relationships. American Journal of Orthopsychiatry, 70, 474-490. https://doi.org/10.1037/h0087681

Obegi, J. (2008). The development of the client-therapist bond through the lens of attachment theory. Psychotherapy Theory, Research, Practice, Training, 45(4), 431-446. https://doi.org/10.1037/a0014 330 
Page, T. F., Heller, S. S., \& Boris, N. W. (2008). A social-emotional assessment method for young children in foster and residential care: The attachment-based narrative story-stem technique. Residential Treatment for Children \& Youth, 23(3-4), 139-162. https://doi.org/10.1080/08865710609512721

Petrowski, K., Pokorny, D., Nowacki, K., \& Buchheim, A. (2013). The therapist's attachment representation and the patient's attachment to the therapist. Psychotherapy Research, 23(1), 25-34.

Pietromonaco, P. R., \& Barrett, L. F. (2000). The internal working models concept: What do we really know about the self in relation to others? Review of General Psychology, 4(2), 155-175. https://doi. org/10.1037/1089-2680.4.2.155

Roisman, G. I., Holland, A., Fortuna, K., Fraley, R. C., Clausell, E., \& Clarke, A. (2007). The adult attachment interview and self-reports of attachment style: An empirical rapprochement. Journal of Personality and Social Psychology, 92(4), 678. https://doi.org/10.1037/0022-3514.92.4.678

Siegel, D. (2007). The mindful brain: Reflection and attunement in the cultivation of well-being. New York, NY: W.W. Norton \& Company.

Siegel, D. (2015). The developing mind: How relationships and the brain interact to shape who we are (2nd ed.). New York, NY: Guilford Press.

Siegel, D. J., \& Bryson, T. P. (2011). The whole brain child: 12 revolutionary strategies to nurture your child's developing mind. New York, NY: Delacorte Press.

Sonkin, D. J. (2005). Attachment theory and psychotherapy. California Therapist, 17(1), 68-77.

Substance Abuse and Mental Health Services Administration. (2018). Trauma-informed approach and trauma-specific interventions. Retrieved from https://www.samhsa.gov/nctic/trauma-interventions

Tortora, S. (2006). The dancing dialogue: Using the communicative power of movement with young children. Baltimore, MD: Paul H. Brookes Publishing.

Tortora, S. (2010). Ways of seeing: An early childhood integrated therapeutic approach for parents and babies. Clinical Social Work Journal, 38(1), 37-50. https://doi.org/10.1007/s10615-009-0254-9

Tuma, J. M. (1989). Mental health services for children: The state of the art. American Psychologist, 44(2), 188-199. https://doi.org/10.1037/0003-066X.44.2.188

van der Kolk, B. A., Roth, S., Pelcovitz, D., Mandel, F., \& Spinazzola, J. (2005). Disorders of extreme stress: The empirical foundation of a complex adaptation to trauma. Journal of Traumatic Stress, 18(5), 389-399. https://doi.org/10.1002/jts.20047

Vermes, K. (2011). Intersensory and intersubjective attunement: Philosophical approach to a central element of dance movement psychotherapy. Body, Movement and Dance in Psychotherapy: An International Journal for Theory, Research and Practice, 6(1), 31-42. https://doi.org/10.1080/17432 979.2010 .533823

Von Glasersfeld, E. (2005). Introduction: aspects of constructivism. In C. T. Fosnot (Ed.), Constructivism: Theory, perspectives, and practice. New York, NY: Teachers College Press.

Winnicott, D. W. (1960). The theory of the parent-infant relationship. The International Journal of Psycho-Analysis, 41, 585.

Winnicott, D. (1965). The maturational processes and the facilitating environment: Studies in the theory of emotional development. New York: International Universities Press.

Wolfe, C., \& Wittenborn, A. K. (2012). Resident and counselor relationships in a court-affiliated residential treatment setting for adolescents: Role of attachment. Journal of Family Psychotherapy, 23(4), 255-272. https://doi.org/10.1080/08975353.2012.735587

Young, J. (2017). The therapeutic movement relationship in dance/movement therapy: A phenomenological study. American Journal of Dance Therapy, 39(1), 93-112. https://doi.org/10.1007/s1046 5-017-9241-9

Zegers, M. A. M., Schuengel, C., Van Ijzendoorn, M. H., \& Janssens, J. M. A. M. (2008). Attachment and problem behavior of adolescents during residential treatment. Attachment \& Human Development, 10(1), 91-103. https://doi.org/10.1080/14616730701868621

Publisher's Note Springer Nature remains neutral with regard to jurisdictional claims in published maps and institutional affiliations.

Emma Mamis, MA, R-DMT is a dance/movement therapist and counselor. She is a graduate of Columbia College Chicago's Dance/Movement Therapy \& Counseling program and studied psychology at the University of California, Riverside. Emma has worked with children in a variety of settings helping 
them overcome various forms of trauma. Additionally, she has worked closely with survivors of domestic violence, immigrants, and individuals overcoming substance use. Emma's written works include her Master's Thesis: An Embodied Artistic Inquiry into Attachment-Oriented Therapeutic Relationships, and her Undergraduate Capstone: Redefining Gender Roles in Same-Sex Couples in Collegiate Dancesport. Emma was a co-presenter at the 2020 American Dance Therapy Conference (A New Phrase for Violence: Understanding Domestic Violence and Culturally Relevant Interventions in Dance/Movement Therapy). Emma continues to work as a dance/movement therapist and strives to advocate for diverse and holistic services for those in need regardless of background, language, sexuality, and gender-identity.

\section{Affiliations}

\section{Emma K. Mamis ${ }^{1}$}

Emma K. Mamis

emma.mamis@gmail.com

1 Columbia College Chicago, Chicago, IL, USA 